\title{
The other side? Das implicações morais de certos horizontes imaginativos na África do Sul
}

The other side? On moral implications of certainimaginative horizons in South Africa

\section{Laura Moutinho}

\section{(2) OpenEdition Journals}

Edição electrónica

URL: http://journals.openedition.org/aa/1403

DOI: 10.4000/aa. 1403

ISSN: 2357-738X

\section{Editora}

Programa de Pós-Graduação em Antropologia Social (UnB)

Edição impressa

Data de publição: 1 dezembro 2015

Paginação: 77-97

ISSN: 0102-4302

Refêrencia eletrónica

Laura Moutinho, «The other side? Das implicações morais de certos horizontes imaginativos na África do Sul», Anuário Antropológico [Online], v.40 n.2 | 2015, posto online no dia 01 junho 2018, consultado o 28 abril 2021. URL: http://journals.openedition.org/aa/1403 ; DOI: https://doi.org/10.4000/aa.1403

\section{(c) $($ ) $\odot \odot$}

Anuário Antropológico is licensed under a Creative Commons Atribuição-Uso Não-Comercial-Proibição de realização de Obras Derivadas 4.0 International. 


\section{The other side? Das implicaçóes morais de certos horizontes imaginativos na África do Sul*}

Laura Moutinho

USP

\section{Introdução}

Algumas experiências vividas no trabalho de campo se transformam em marcas indeléveis. Há momentos, ou ao menos pode haver alguns, profundamente perturbadores em termos etnográficos, existenciais e morais. A situação mais desconcertante que vivenciei ocorreu em Ventersdorp, na África do Sul, em abril de 2010. Na época, eu realizava trabalho de campo na Cidade do Cabo quando um nacionalista africânder pró-apartheid foi assassinado enquanto dormia em sua fazenda por dois homens negros. A comoção social, os rumores acerca do crime (que mobilizavam razóes ora trabalhistas, ora raciais ou sexuais) e o medo de uma guerra racial se espraiaram pelas ruas, pelos jornais, pelo rádio e pelos noticiários da televisão.

Assim que o assassinato veio a público, falou-se em morte por questôes trabalhistas: Eugène Terre'Blanche não estaria pagando os salários dos seus funcionários, que resolveram então se vingar. A segunda versão foi a racial e alimentava todos os fantasmas do apartheid a respeito do extermínio e/ou da expulsão dos africânderes da África do Sul. A terceira versão causou espanto e rebuliço, pois, como Terre'Blanche foi encontrado com as calças arriadas até os joelhos, veiculou-se que ele estaria numa festinha íntima e etílica com os dois rapazes, e que desentendimentos típicos de crimes homofóbicos teriam levado ao assassinato. Outros falaram de estupro seguido de morte. Estávamos às vésperas da Copa do Mundo de 2010, que foi realizada na própria África do Sul. O episódio teve, portanto, grande atenção da mídia internacional.

Como afirmou Trajano Filho (2008:256), rumores "são como bombas tanto no seu modo de transmissão como na composição". A metáfora se alinha ao clima tenso e belicista que se instaurou com o assassinato. Terre'Blanche morreu exatamente como dizia que os brancos iriam morrer com o fim do apartheid: assassinados enquanto dormiam. Todo esse contexto me levou a pedir autorização ao $\mathrm{CNPq}$, que financiava outro projeto, ${ }^{1}$ para seguir da província do Cabo Ocidental para uma cidade do noroeste sul-africano, a duas horas de carro de Joanesburgo, 
para acompanhar o funeral. Porém, ao contrário dos conflitos na Guiné-Bissau analisados por Trajano Filho, não havia uma ausência de balizamentos morais. Notei, em realidade, um excesso no contexto analisado.

Quando cheguei a Ventersdorp, ao percorrer as ruas da cidade tomadas por pessoas que falavam de um genocídio africânder em curso, conheci o mundo ultrarracista do grupo paramilitar Movimento de Resistência Africâner (Afrikaner Weerstandsbeweging, AWB), que havia sido fundado justamente por Terre'Blanche. Como mencionei, seu assassinato reacendeu muitos dos medos acerca da violência racial que pairavam sobre a África do Sul, especialmente no período da transição para a democracia. Era esse o clima dominante no local.

Naquela complexa experiência, deparei-me, como previa, com um profundo ódio racista ${ }^{2}$ que se fez presente de modo absolutamente visível e arrogante, mas precisei confrontar essa experiência com afetos, dores e almas assustadas com uma perda brutal. Observei o funeral, as manifestaçóes nas ruas e o discurso do pastor da Igreja Africâner Reformada. Observei a reza e os rostos emocionados. Observei meu próprio estranhamento àquilo que me soava, num primeiro momento, próximo de uma loucura coletiva. Aos poucos, fui notando que o que mais me surpreendia em toda a cena, em todo o racismo que eu podia entrever em cada som, gesto, palavra, era o amor partilhado entre aquelas pessoas. Foi assustador notar como esse sentimento está igualmente na base da construção do próprio racismo vivido contra outras pessoas. Lembro-me vivamente de como me senti sufocada. Não somente o ódio produz o horror, foi o que pensei naquele momento.

Percorro uma vez mais essa experiência ao folhear a biografia Eugène Terre'Blanche - My side of the story, de Amos van der Merwe: "the book is dedicated to every child who ever learned to pray in Afrikaans, and to every parent and ancestor who made it possible. May our children have the same privilege", diz o autor. As dedicatórias e os agradecimentos que preenchem a página anterior ao prefácio começam com a citação que reproduzi e terminam com "My family and friends achieved the impossible: they tolerated my fascination with Eugène Terre'Blanche [...]" (Merwe, 2011:04).

Aquele sentimento de estupefação que vivi no funeral retorna com essa leitura: o racista supremo que me foi descrito em detalhes pelos amigos da Cidade do Cabo, cujas ações violentas eram rememoradas nas páginas dos jornais e nas cenas sobejamente repetidas dos noticiários, aparecia nessa narrativa, em contraste, como um destemido e sofrido (porém digno) herói nacionalista africâner. Revejo a cena: as crianças na igreja, tímidas e colaborativas com os mais velhos que passavam mal. Elas me parecem familiares pelo jeito desengonçado de adolescente, mas são igualmente estranhas pela forma como, mesmo distraidamente, seguem as 
rezas. Revejo um deus que afirma ser pecado não ser racista e a igreja tomada de emoção; relembro o carisma viril e militarizado de Eugène Terre’Blanche: a imagem no fundo da igreja ornada com uma coroa de flores o traz montando seu famoso cavalo. Um homem capaz de despertar ódios e adesóes na mesma medida. A bandeira do AWB flamula ainda em minha memória como em cada cena ou situação que, naquele momento, eu me esforçava para observar e entender. $\mathrm{O}$ relativismo próprio do olhar antropológico, marcado justamente por uma perspectiva antirracista se nos ativermos às linhagens inauguradas por Franz Boas e Malinowski, era confrontado por rituais de afirmaçáo do racismo e da separaçáo racial. Em outras palavras, tive dificuldades de conciliar meu próprio relativismo de base humanista com o racismo multifacetado que observei na ocasião. Concomitantemente, no curso desta experiência, compreender esse ponto de vista, seus valores e as motivaçôes começou a me desafiar.

Esse cenário traz uma série de referências que espero colocar em perspectiva neste artigo. Seguindo a biografia de Terre'Blanche, que se pretende um testemunho e um retrato de e para um povo em sua luta para "manter a sua identidade e a sua liberdade", procuro percorrer os usos e os significados, tanto políticos quanto éticos, das ideias de tragédia e sofrimento. A aporia da "tragédia" africânder que irei perscrutar por uma das faces do testemunho de Terre'Blanche expóe uma realidade que excede, para evocar uma expressão de Agamben (2008) acerca de Auschwitz. No caso em tela, a posição de quem a vocaliza também se apresenta como vítima, mas da história num sentido mais amplo. Seu autor foi copartícipe de uma lógica similar de extermínio. Não se trata de qualificar essa narrativa como um relato cínico, mas de compreender os princípios éticos e morais que a sustentam. O sofrimento é mobilizado para explicar a produção da injustiça. Minha intenção é explorar um campo que, ao juntar várias peças de um quebra-cabeça, entendo como contra os direitos humanos, mas que retém um particular sentido de humano. As ideias-chave que delineiam as fronteiras dessa complexa cena são raça e religião, gênero e militarismo.

Nesse sentido, o objetivo deste artigo é percorrer parte da polêmica história de Terre'Blanche e de alguns lances do AWB, tendo como fio condutor sua biografia. Como ficará claro adiante, o AWB é um movimento paramilitar de ultradireita, reconhecido como ultrarracista e separatista, que propunha a criação de um Volkstaat, palavra africâner que indica a criação de uma República Bôer independente da África do Sul. Não é simples voltar o olhar para um personagem tão complexo e tido com the evil para muitos sul-africanos.

A análise se inspira nas provocativas reflexôes de Jacklyn Cock em The place of gender in a demilitarisation agenda (1993). A socióloga sul-africana questiona 
o lugar do militarismo na soluçáo não somente de conflitos, mas igualmente da violência e da desigualdade social e de gênero. Cock realiza uma análise corajosa, uma vez que, ao abordar gênero e militarização, traz à cena, em relativa posição de igualdade, a virilidade que informa a violência e o militarismo de africânderes e zulus. A reflexão que se segue faz ainda uma defesa da importância da articulação entre gênero e raça na análise de certas cenas sociais.

David Welsh, que abordou a emergência do terrorismo de ultradireita na África do Sul, enfrenta uma questão recorrente entre os autores que se debruçaram sobre a história dos africânderes. $\mathrm{O}$ autor questiona se "[...] it was a continuation of that strand of afrikaner nationalism which, historically, has had a romantic, even Faronesque, view of violence as an instrument of liberation" (1995:249). Tratase de uma questáo complexa. Abordemos esse ponto com base na narrativa de Terre'Blanche para entender e situar tanto as formaçóes discursivas, as açóes e a violência do racismo da ultradireita sul-africanas, que forjaram políticas e sujeitos, quanto o sentido de "injustiça" operado por muitos dos nacionalistas africânderes.

A ideia de "militarismo" que guia a reflexão que se segue acompanha outro debate conduzido por Cock (2004): não se trata de pensar em instituiçôes militares per se, mas tentar lançar luzes sobre uma cultura militar que se inscreve em amplos domínios sociais, forjando uma concepção militarizada de cidadania. Na pesquisa, venho notando que cada vez mais se afirma uma noção belicista tanto de raça quanto de gênero nesse contexto. Se inicialmente refleti sobre a regulação do racismo do ponto de vista legal na análise dos processos criminais contra casais e amantes inter-raciais, com a pesquisa atual acessei uma cosmologia racial de ordem moral que mobiliza um deus racista e belicoso. Inspirada na reflexão de Trajano Filho (2011:220), notei a forma como a militarização das relaçôes raciais trabalha não somente para impossibilitar o contato físico inter-racial, mas igualmente para conter qualquer possibilidade de empatia por meio de um "ethos autoritaire qui se manifeste par les attitudes corporelles et le comportement verbal du militaire", que envolve o controle das emoçóes e uma profunda rigidez dos códigos de conduta.

McGill Alexander (2000) argumenta que a face militarizada do nacionalismo africânder que chegou ao poder com a instalaçáo do apartheid, em 1948, impôsse mediante um aparato legislativo que contou com a South African Defense Force como veículo para disseminar a cultura africânder sobre setores brancos da sociedade - e não apenas estes, tendo em vista, por exemplo, a obrigatoriedade do ensino do africâner nas escolas. Não se trata, assim, de circunscrever sua força às açôes militares da "guerra contrarrevolucionária", embora seu poderio e sua importância sejam inegáveis. 
De fato, a relação entre a África do Sul e os países vizinhos não foi jamais igualitária. Ainda que Moçambique e África do Sul, por exemplo, tenham histórias coloniais diferenciadas (e em parte radicalmente distintas, se nos ativermos, por exemplo, à questão racial), a relaçáo entre os dois países sempre foi estreita e complexa: desde o apoio dado pela África do Sul à Renamo contra a Frelimo na guerra civil que assolou Moçambique após a independência de Portugal, ${ }^{3}$ passando pelo refúgio oferecido por Moçambique aos que lutaram contra o apartheid (como Ruth First e Albie Sachs), pelo acesso ao sistema de saúde sul-africano pelos moçambicanos (são muitos os que pegam ônibus em Maputo para se tratar em hospitais sul-africanos, especialmente em Joanesburgo) e, ainda, pela imigração em busca de emprego e trabalho, como no caso das minas sul-africanas.

Döpcke (1998) recorre a expressóes como "imperialismo sul-africano" e "colonial" ao qualificar as açóes políticas e econômicas sul-africanas que visavam manter o controle e a sua hegemonia na África Austral. Nas palavras do autor,

o intercâmbio na região é caracterizado como "colonial", destacando-se o fato de que a África do Sul considera os países vizinhos como "mercado natural” para os produtos de sua indústria secundária. Por outro lado, o termo amplamente usado para caracterizar a situação dos Estados vizinhos em relação à África do Sul, é dependência. Nos anos 80, o grau de dependência para com a África do Sul variava muito entre os Estados individuais: de dependência e vulnerabilidade absoluta (no caso dos BSL-states e Namíbia), dependência média (Zimbábue, Moçambique, Zâmbia) até dependência relativamente baixa (Angola) (Döpcke, 1998:137).

Foi somente no início da década de 1990, com o fim do apartheid e a democracia, que a África do Sul redefiniu uma atuação política regional que havia sido marcada pela desestabilização dos países vizinhos e por açôes de guerra (mesmo que não declaradas oficialmente).

\section{Algumas palavras sobre a pesquisa}

Faz-se necessário esclarecer que a análise aqui proposta está alinhada a uma agenda de pesquisas sobre o tema. Anteriormente, perscrutei essa temática em outra perspectiva. Na discussáo sobre o Moral Regeneration Movement (Moutinho, 2012), interpelei a ordem moral humanista que sustenta as democracias recentes por meio da análise das tensóes presentes no Movimento de Regeneração Moral (MRM). Investiguei o percurso de uma tática de governamentalidade (Foucault, 1979) tida como necessária para conter a onda de criminalidade que assombrava o país após o fim do apartheid, por iniciativa de Nelson Mandela, ${ }^{4}$ com toda a 
sua força moral, e que se estendeu pelas administraçôes de Thabo Mbeki e do controverso presidente Jacob Zuma. ${ }^{5}$

Mais particularmente, após um conjunto de investigaçôes em que analisei novos regimes de produção e de reconhecimento de sujeitos com o objetivo de iluminar, desde a perspectiva de gênero, raça e sexualidade, um extenso cenário de transformaçóes que tanto inspiraram o campo dos direitos humanos contemporaneamente, ${ }^{6}$ voltei meu olhar para um cenário distinto. Meu objetivo último com esta agenda de pesquisas é inquirir um conjunto de racionalizaçóes e crenças que tanto evita as implicaçóes morais de certos horizontes imaginativos na África do Sul quanto legitima e conclama adesóes mais ou menos disfarçadas a narrativas de cunho racial e separatista.

No presente artigo, estarão novamente em evidência alguns dos sentidos e dilemas políticos e morais evidentes no pós-apartheid a respeito das ideias e experiências de raça e racismo em sua articulação com gênero, tendo como pano de fundo a regulação da sexualidade. Como argumentei anteriormente, o apartheid se ergueu operando a gestão da sexualidade por meio da raça e do racismo. A criminalização do sexo e do casamento inter-raciais operouse conforme a Immorality Act e a Mixed Marriage Act, duas das primeiras leis constituidoras do regime de separação (Moutinho, 2004a, 2004b; Ribeiro, 1995). No entanto, a dimensão concomitantemente moral e religiosa dessa construção, assim como sua teimosa perenidade, somente ficaram mais evidentes para mim no trabalho de campo que realizei em 2010. Se a ideia de raça e a prática do racismo predominantes no apartheid cristalizaram-se pela força de sua face secularizada, sua institucionalização legal no período tem origem numa moral religiosa veiculada especialmente pela Igreja Holandesa Reformada.

O regime de separação definiu formas de cidadania segundo critérios raciais, assentadas numa noção de humanidade construída (e legitimada) de "acordo com as leis de Deus" tal como a compreendeu a Igreja Holandesa Reformada. $\mathrm{Na}$ Rainbow Nation, ${ }^{7}$ em sua recusa à ideia de raça, Ubuntu ${ }^{8}$ aparece como categoria também religiosa, mas agora de origem africana. Essa categoria cria um elo, deslocando-se assim da ideia de diferenciação racial à de humanidade e, consequentemente, de reconhecimento igualmente diferenciado por parte do Estado. A pesquisa que ora realizo vem justamente confrontando essas diferentes e contraditórias perspectivas. 


\section{O contexto político da instalaçáo do apartheid e a luta pela democracia: breves notas}

Poucos povos são descritos, em gêneros diversos, com tanto desprezo como os africânderes. Poucas vezes me deparei com um autor que fizesse isso de modo mais erudito e ambíguo no manejo da ideia de raça que Hannah Arendt em Origens do totalitarismo. Vejamos as palavras da autora. Seus termos são duros e mesmo dúbios, se focarmos a ideia de raça veiculada:

[ ...] os Bôeres foram o primeiro grupo europeu a alienar-se completamente do orgulho que o homem ocidental sentia em viver num mundo criado e fabricado por ele mesmo. Tratavam os nativos como matéria-prima e viviam à custa deles como se vive dos frutos de uma árvore. Preguiçosos e improdutivos, concordaram em vegetar mais ou menos no mesmo nível em que as tribos negras haviam vegetado por milhares de anos (Arendt, 1989:224).

Para Arendt (e muitos outros autores posteriores dizem isso de alguma forma), o que assustou, mas também encantou os europeus foi associar os nativos (humanos) à natureza (não humana). Estabelece-se nesse ponto uma relação metonímica: natureza-animais-seres humanos. Se a natureza "despreparada e inculta” era matéria-prima dos que habitavam a região, para Arendt, o mesmo processo absorveu os bôeres que exploraram humanos como estes haviam explorado a natureza. Provocativamente, no ano seguinte à instalação do apartheid e apenas quatro anos após a Segunda Guerra Mundial, a autora afirma que os bôeres, especialmente os mais pobres, diferenciavam-se dos escravos apenas na cor da pele. Eles estavam separados, mas formavam um conjunto.

$\mathrm{O}$ aspecto da reflexão de Arendt que interessa à presente análise refere-se à articulação entre religião, raça e racismo. O racismo como forma de exploração seria anterior ao seu uso político como parte do ideário do imperialismo. A dominação com base na raça seria fruto da experiência e do convívio - em especial, fruto do fato de que, por mais que os bôeres tentassem negar humanidade aos africanos, sua própria humanidade se afirmava de modo inquestionável. Para serem iguais, e há aqui um fundo de igualdade que não se pode negar, teriam que ser diferentes, hierárquica e desigualmente. Vejamos o que diz a autora: "no entanto, a despeito de todas as explicaçôes ideológicas, o homem negro insistia em conservar suas características humanas, só restando ao homem branco reexaminar a sua própria humanidade e concluir que, nesse caso, ele era mais do que humano, isto é, escolhido por deus para ser o deus do homem negro" (Arendt, 1989:225).

Os bôeres nesse ponto se aproximam dos judeus: ambos comungam a ideia de que são "o povo" escolhido. A diferença, para Arendt, é que no caso dos primeiros 
a escolha divina apenas alimentava a dominação de um grupo sobre o outro: certos trabalhos não poderiam ser executados por uma raça superior. A Igreja Holandesa Reformada estava tão infensa à consciência humanista veiculada por outras denominaçóes cristâs, negando veementemente a origem comum da humanidade, que em 1944, apenas quatro anos antes da instalação do apartheid, adotou uma moção "que se opunha ao casamento de bôeres com cidadãos de língua inglesa” (Arendt, 1989:225, nota 22). O argumento, nesse caso, era o trabalho dos missionários cristãos na região do Cabo. Mas tudo, em realidade, é um pouco mais complexo. Vejamos a seguir as primeiras cenas do apartheid e como elas dialogam com o presente e o passado sul-africano.

Daniel François Malan tornou-se, em 1948, o primeiro-ministro do Estado que instalou a policy of separate development, maneira como o apartheid foi oficialmente nomeado. O National Party (NP), do qual Malan era um dos fundadores, foi formado por uma coalizão entre o Herenigde Nasionale Party e o Afrikaner Party, derrotando o United Party, de Jam Smuts. Malan era pastor da Igreja Holandesa Reformada e filósofo. Hyslop (1995) argumenta que ele teve um papel extremamente importante na disseminação da ideia de que os casamentos inter-raciais e a miscigenação eram pecados. Esse foi um argumento determinante para a instalação do apartheid e para a chegada ao poder de Malan e do NP (Moutinho, 2004a).

Como discuti anteriormente (Moutinho, 2004a), os casamentos inter-raciais emulam a ideia de que a miscigenação é poluidora (Douglas, 1967), mas além disso é preciso ter em mente que a aversão à mistura foi mobilizada também pela proletarização da mulher africâner e pelas mudanças sociais e políticas introduzidas a partir de 1930, como o direito ao voto, a urbanização e a crise econômica, que empurraram essas mulheres para o mercado de trabalho. Mesmo antes da instalação do apartheid, havia leis que criminalizavam e regulavam os contatos sociais e íntimos entre raças. Os blacks ou natives estiveram desde sempre em posição de exclusão e subjugação. Embora fossem os homens negros que aparecessem como o potencial perigo na produção da miscigenação — por meio do casamento ou do estupro - , era o crescente poder econômico dos indianos que ameaçava economicamente o lugar de poder dos homens africâneres. O "populismo racial” foi, nesse momento, diretamente conectado às transformaçóes nas relaçóes de gênero e de classe. $\mathrm{Na}$ literatura sobre o tema, frequentemente se tem a impressão de que, quando se fala em classe, a questão de fundo que ganha mais relevo é gênero.

Neste ponto, vale retornar ao argumento de Jacklyn Cock. Masculinidade e militarismo estiveram frequentemente ligados ao nacionalismo. Em sua análise, 
a autora escapa do literalismo (Crapanzano, 2000) característico das análises sulafricanas e mesmo estadunidenses a respeito do racismo e do gênero, trazendo a questão do militarismo e da violência como solução legítima para conflitos como parte de uma estrutura social mais ampla que diz respeito aos bôeres, aos zulus e a outros grupos étnicos e raciais.

A primeira de uma sequência de leis que instaurou o regime de separação foi a Lei de Criminalização dos Casamentos Mistos, de 1949. Tratou-se de uma promessa de campanha cumprida no ano seguinte à vitória eleitoral (Moutinho, 2004a). Em seguida, foram aprovadas as leis que desenharam o regime de segregação: Lei de Registro Populacional (1950), que delimitava os grupos raciais white, coloured/ indian e native; Lei de Áreas de Agrupamento (1950), que fixou áreas residenciais específicas para os grupos raciais; Lei da Imoralidade (1950), que criminalizou o intercurso sexual inter-racial; Lei da Criminalização do Comunismo (1953), que baniu os partidos de esquerda; e Lei de Reserva dos Benefícios Sociais (1953), que instituiu a segregação espacial nos espaços públicos e dispositivos urbanos.

Como muitos outros nacionalistas africânderes, Malan opôs-se à entrada da África do Sul na Segunda Guerra Mundial. As feridas eternamente abertas da II Guerra Anglo-Bôer foram determinantes para alimentar a antipatia dos africânderes por uma guerra em que teriam que lutar ao lado dos ingleses. Mas a proximidade do nacionalismo africâner com o ideário nazista não pode ser ignorada. De todo modo, a vitória do NP e de seu discurso marcado pela unidade étnica ocorreu com uma pequena margem de votos. Nas duas décadas seguintes, as medidas legais e autoritárias consolidaram e fortaleceram não somente a segregação, como também o nacionalismo africâner.

Malan esteve no comando da África do Sul até 1954. Verwoerd assumiu no início do governo de Malan, em 1950, o Ministry of Native Affairs. Ele é tido como o responsável pela estrutura legal do apartheid e esteve à frente do processo que transformou a África do Sul em república, em 1961. Verwoerd tornou-se primeiro-ministro após a morte de Johannes Gerhardus Strijdom, que havia substituído Malan, ocupando o cargo até seu assassinato em 1966. Nascido na Holanda, era um africâner por formaçáo, e implementou o chamado grande apartheid. Verwoerd aparece na historiografia sul-africana com destaque. Conhecido como "o arquiteto do ódio", foi recorrentemente citado no trabalho de campo que realizei entre os simpatizantes do AWB. Muitos inclusive mantêm uma foto de Verwoerd na sala de suas casas. Suas ideias têm uma força perene entre muitos dos simpatizantes do apartheid. Interessa aqui destacar duas delas: foi defensor da causa poor white e opôs-se à imigraçáo judaica no período da perseguição nazista. 
Um primeiro sinal de mudança, que para alguns pode ser entendido como uma abertura aos grupos paramilitares de ultradireita, foi a criação do Hersitigte Nasionale Party (HNP), em 1969. O partido surgiu como consequência de medidas tidas como de flexibilização pelos nacionalistas africânderes mais radicais, promovidas por B. J. Vorster, que foi primeiro-ministro da África do Sul entre 1966 e 1978. David Welsh, em uma análise sobre a emergência do terrorismo de direita na África do Sul, argumenta que uma postura mais "reformista" do NP expôs a ultradireita, que estava acomodada de modo mais ou menos invisível no partido. O HNP não teve uma votação expressiva nas eleiçóes de 1970, mas se manteve ativo na disseminação de suas ideias.

Em 1978, P.W. Botha tornou-se primeiro-ministro. Aqueles foram anos extremamente turbulentos. De um lado, o governo precisava enfrentar o boicote internacional; de outro, os protestos contra o fim do apartheid intensificavam-se internamente. Assim, considerando o movimento da ultradireita no período, o surgimento do Conservative Party (CP), em 1982, aparece de modo muito mais significativo. No esforço de manter o apartheid ativo para os blacks, Botha ampliou, na nova Constituição, as esferas de poder e atuação dos coloureds ${ }^{10} \mathrm{e}$ indians. O CP teve uma votação expressiva em 1983, no referendo entre o eleitorado branco que ratificou a nova Constituição. Além disso, nas eleiçôes de 1987 e 1989, aumentou o espaço do partido, que recebeu um terço dos votos dos white.

\section{A autobiografia de Eugène Terre'Blanche: a versáo que confronta uma aversáo}

Amos van der Merwe descreve Terre'Blanche como um homem capaz de inspirar as massas, que acreditou que as próprias açôes iriam beneficiar o povo e que alimentou as aspiraçóes de um nacionalismo africâner. Há outro aspecto importante no relato: Terre'Blanche "perdeu tudo em que acreditava". Em tom dramático e vitimizador, sua vida é narrada como um "retrato" do que aconteceu com muitos sul-africanos. Nas suas palavras, "despite the facts, the history and the memories, the loss of our independence leaves a void in our national being and many ex-nationalist Afrikaners still find it difficult to make peace with the present circumstances" (Merwe, 2011:6).

O livro de Terre'Blanche é e se pretende incômodo: o percurso existencial de um homem que se quer - e é visto por alguns — como o espelho do seu grupo. A narrativa segue a primeira pessoa, como se fosse Terre'Blanche escrevendo uma reflexão sobre a própria experiência. $\mathrm{O}$ texto póstumo, entretanto, foi organizado por Merwe de forma não a mostrar fatos novos, mas partilhar a trajetória do biografado em uma prosa intimista, introspectiva e conotativa. 
Nos 21 capítulos que compóem o livro, termos de caráter avaliativo mesclamse com os volitivos, destacando a luta e a identidade africânderes. Há uma epígrafe na abertura do livro, uma página com emocionadas dedicatórias, um pós-escrito e uma bibliografia de referência em inglês e africâner ao final. Cada capítulo traz, também, uma epígrafe. A autobiografia foi publicada em inglês em 2011 e, na contracapa, somos informados de que a versão em africâner estava pronta quando da morte de Terre'Blanche. Ainda nesse espaço, é dito ao leitor que o autor escreveu o livro com a cooperação de Terre'Blanche, que narra, portanto, a sua vida de modo autobiográfico. A editora do livro chama-se Griffel. O site da editora, indicado no livro, é fechado a visitaçôes. No endereço, encontramos apenas a seguinte mensagem: "Domain reserved on behalf of our client". Não é possível encontrar qualquer informação na internet a respeito da editora, mas o livro teve boa distribuição. Comprei meu exemplar, uma versão em inglês do original em africâner, no aeroporto de Joanesburgo, e encontrei outros na Exclusive Books, uma livraria com filiais em várias cidades da África do Sul.

A capa dessa edição não possui fotos. A imagem abstrata se diferencia completamente da edição em africâner, que foi publicada em maio de 2010, menos de um mês depois do assassinato do biografado. Esta última traz uma fotografia de Terre'Blanche, similar à que circulou no funeral, que ocupa toda a capa, com seu nome escrito na altura da testa e o nome do autor, em letras bem menores, ao final da página, onde fica o queixo e a barba grisalha. Nessa foto, destacam-se a seriedade do semblante, as rugas profundas, a calvície sob os cabelos brancos, os olhos azuis e a pele branca com traços de muita exposição ao sol. O título também é diferente: na edição em africâner e logo abaixo do nome do líder do AWB, lemos "My Storie". Na fotografia também é possível entrever parte de uma camisa que parece o uniforme do grupo paramilitar que liderou. Há uma versão em $e$-book escrita em africâner. A capa da edição em inglês traz um projeto gráfico abstrato que joga com as cores preta e branca. $\mathrm{O}$ nome de Terre'Blanche está em destaque, escrito numa faixa preta com letras brancas. "My side of the" aparece em cor negra num fundo branco, e "story" está escrito em branco com letras enormes sobre uma faixa negra. A letra R de story está cortada ao meio. Lembro que Terre'Blanche foi assassinado com um facáo. Todo o título está respingado por manchas brancas e pretas, que evocam sangue. O nome do autor também pode ser lido no final da página, em letras bem menores que a versão em africâner. O livro foi publicado em 2011, está esgotado e não possui edição digital.

Amos van der Merwe esclarece ainda que a pesquisa sobre a vida e a carreira de Terre'Blanche segue parte da busca por sua própria identidade, mas ele 
mesmo jamais se envolveu pessoalmente com as políticas de direita tal como Terre'Blanche. Merwe vive na região do Cabo, é médico, mas sonha viver um dia apenas de literatura. Ele publicou outro livro nos Estados Unidos, intitulado Facing surgery with Christ, por uma editora independente, que possui valores cristãos, de propriedade familiar, e tem por "missão" descobrir novos autores. O site da Tate Publishing explicita seus objetivos: "have you written a book? Are you looking for a publisher? Have you searched out and submitted your manuscript to dozens of publishing companies only to be turned away, time and time again? If you've answered yes to any of these questions, Tate Publishing could be your answer".

O livro está direcionado a um público cuja definição é possível encontrar logo no primeiro capítulo: os jovens. Há solidão, há poesia, há perdas emocionais e econômicas, há uma marcante reflexividade que recorre a uma linguagem de vitimização próxima daquela que se pode encontrar nos sujeitos que vocalizam o lado menos visível da desigualdade social e da violência. A construção desse personagem como vítima ou como mal compreendido náo é nova. Os próprios africânderes se apresentam como vítimas da história: dos ingleses, dos judeus, do capitalismo, do comunismo, dos negros, dos direitos humanos e, sobretudo, da incompreensão mundial com a "sua situação" na África do Sul.

Os ideólogos da democracia recém-instaurada e os defensores do apartheid comungam certo entendimento: a sociedade para ambos é definida como "desigual". Aqueles, entretanto, a entendem como algo a ser superado, e estes últimos, como desejável. A ideia de raça é outro ponto em comum e segue a mesma lógica. Para uns, é uma categoria a ser superada, uma vez que instala a desigualdade social; para outros, trata-se da afirmação de uma diferença intransponível entre os seres humanos: a desigualdade necessária.

"It is the silence that causes fear at night" (Merwe, 2011:25). Assim se inicia o capítulo Rooigrond ("terra vermelha" em africâner). A narrativa opera contrastivamente entre o silêncio e a clausura da prisão, ${ }^{11}$ de um lado, e as imagens que evocam a amplitude das savanas africanas, de outro. Numa linguagem intimista e reflexiva, que procura capturar o leitor com sentidos e metáforas visuais, vemos surgir o autorretrato de um herói nacionalista que teve que se dobrar à lei, mas que não terá seu "espírito quebrado". Faisóes, leôes, galopes a cavalo e a natureza exuberante da fatherland são um contraste para o corpo preso a uma cela. Terre'Blanche afirma que sabe que não conquistará o inimigo com a força bruta, mas "the victory that I seek, lies in the survival of my unique individuality, my very being as an Afrikaner" (Merwe, 2011:26). Ele se apresenta como um bode expiatório, um exemplo de que o nacionalismo white foi sufocado. Todo 
o processo de reconhecimento moral do racismo e do apartheid como injustiças e crimes contra os direitos humanos é representado sob a ótica do engodo. Nas palavras de Terre'Blanche,

[...] the masses of people sleeping in shacks and squatter camps tonight, do not care that the government is allowing the infrastructure of the country to be destroyed. They want the political satisfaction of knowing that the erstwhile oppressors are punished. They want to see justice being done to the oppressed and the warriors who fought for their freedom. [...] For them my imprisonment is an emotional relief, drawing their attention away from the miserable existence of their daily lives (:26).

Para Terre'Blanche, a democracia não contempla necessidades individuais e, no continente africano, isso significa que o grupo que controla o parlamento tem liberdade para proteger e promover os próprios interesses.

Ao descrever seu sonho de independência e sua luta pela liberdade, Terre'Blanche se eleva ao status e ao drama de grandes líderes africânderes como Paul Kruger (político e militar que foi presidente da África do Sul de 1883 a 1900 e morreu no exílio, ele acrescenta); Jam Smuts (militar, político e primeiroministro da África do Sul em duas ocasiôes, de 1919 a 1924 e de 1939 a 1948, que compreendeu erroneamente o momento político, segundo Terre’Blanche); Hendrik Verwoerd (o já mencionado "arquiteto do apartheid", que era psicólogo e sociólogo, e que foi primeiro-ministro da África do Sul entre 1958 e 1966, assassinado no próprio parlamento); e P. W. Botha (que foi ministro da Defesa em 1966, primeiro-ministro entre 1978 e 1984 e presidente da África do Sul entre 1984 e 1989). Botha, que aumentou enormemente a capacidade militar sulafricana na década de 1980, protagonizou um programa militar em parceria com Israel e, na tentativa de reverter o boicote econômico, ampliou, como mencionei, as cadeiras no parlamento para os coloureds e indians, é citado como alguém que morreu solitário e amargo. Com uma voz que ecoa da solidão de seu cárcere, Terre'Blanche se pergunta: "do I then have any chance at all to pave a way where the others had failed?" Com essas palavras e referências, ele narra então a sua jornada de luta pela manutenção da identidade de seu povo. Entre os episódios e ações, ganha destaque o grupo paramilitar AWB.

\section{Afrikaner Weerstandsbeweging (AWB)}

No sétimo dia do mês 7 de 1973, sete homens criaram o Afrikaner Resistance Movement (AWB) numa obscura garagem de Heidelberg, na província de Gauteng. A sequência de números 7, bem como a oposição ao 666 (o número 
da besta em oposição ao de deus), foi grafada na bandeira do grupo. Essa é uma explicação recorrente. Os membros do AWB a manejam a fim de se contrapor ao argumento de que a bandeira e a combinação dos números sete evocam a suástica. O movimento esteve sob a liderança de Terre'Blanche — fazendeiro bôer e antigo membro da força de segurança nacional conhecida como South African Police (SAP) — desde sua criação até o assassinato desse líder, em Ventersdorp, em abril de 2010.

As duas características acima mencionadas são centrais. Terre'Blanche argumenta em sua biografia que, como ele era membro da SAP, tinha acesso a informaçóes ocultadas para os demais. $\mathrm{O}$ que as informaçóes teriam trazido? Em resumo, a aniquilação de um grupo. Os interesses dos africânderes iriam ser "sacrificados" em nome da "sobrevivência política", defendeu Terre’Blanche e vários outros. O "sacrifício" seria a perda da religião, da cultura e da história africânderes. O receio principal se dirigia ao "nacionalismo negro", mas Terre'Blanche menciona ainda o governo e o Partido Nacional. Em sua narrativa confessional, o mito de origem do AWB e de todas as formas de evocação do número 7 como divino, em oposição ao 666, introduz ainda o racismo como uma missão divina e o militarismo como seu veículo.

A missão divina é belicosa: o AWB é descrito como "born out of national pride, reared in anger and distrust, locked up by fear. Wounded, but unvanquished" (Merwe, 2011:10). A criação do AWB está conectada a uma série de eventos assim caracterizados: "we were intensely aware of the events of the previous day". Especificamente, Terre'Blanche argumenta que não estariam imunes aos ataques do nacionalismo negro. Há uma sequência de acontecimentos que sustentam a tese: a prisão e perda de direitos de 270 pessoas na Rodésia (atual Zimbábue); os assassinatos do processo de descolonização do Quênia, na Revolta Mau Mau; e circunstâncias similares em Zâmbia, Malawi e Moçambique. Nelson Mandela foi lembrado também — não como o grande ícone moral de uma nação, mas como aquele que havia sido preso por ter cometido uma alta traição. Mas nem isso, ele argumenta, iria segurar a ação do African National Congress, o ANC.

Terre'Blanche relembra que o ANC havia veiculado que eles iriam usar as massas negras pela democracia. Uma citação de Paul Kruger é utilizada para dar mais uma ideia a respeito do que a democracia representa e representou para esse grupo: "it is not the vote you want, it is my country you want to take" (Merwe, 2011:10). Para os nacionalistas africânderes, essa frase ainda ecoa como uma verdade: "people still want to take out our Bôer country under the pretence of the right to vote" (Merwe, 2011:10). Como afirma Anne McClintock, 
[...] todas as histórias de gênese são histórias de poder político e toda publicação envolve delegação de autoridade. Edward Said observa que a própria palavra "autor" deriva da mesma raiz etimológica de "autoridade" e é acompanhada de fortes noçóes de engendramento, domínio e propriedade. A entrada na autobiografia, particularmente, é vista como entrada na autoridade da autorrepresentação (2010:435).

Em My side of the story, a linguagem do sofrimento legítimo e a luta daqueles que buscaram representação e reconhecimento numa longa história de violência racial e de gênero são mobilizadas e reconstruídas do ponto de vista dos que perderam algo: o poder que instituiu o apartheid como "desenvolvimento em separado", em 1948. A linguagem do livro é familiar, mas paradoxal, pois os sofrimentos físicos e morais instituem e buscam legitimar o racismo, e não a sua erradicação. No enquadramento de Eugène Terre'Blanche, tem me interessado particularmente seguir a pista explorada por Veena Das (2007), com base nas análises de Judith Butler e Jitendra Mohanty, sobre a força da experiência de sujeição na constituição de sujeitos, especialmente $o$ sentido particular de sujeição com o qual operam os africânderes para, nessa direção, dar inteligibilidade à zona discursiva ocupada por esse testemunho. Diferentemente do trabalho realizado pela Comissão de Verdade e Reconciliação, no sentido de superar os traumas do passado, o ressentimento é reivindicado nesse cenário de modo a afirmar e manter posiçóes.

O tempo, da maneira como manejado por Veena Das (1999), não realiza aqui o seu trabalho. $\mathrm{O}$ tempo mobilizado pelo ressentimento não está engajado em mudanças. O nacionalismo africânder e o desejo de construir um Estado independente, ${ }^{12}$ moldados pela narrativa intimista, com tons dramáticos que desenham a injustiça vivida, sáo operadores lógicos tanto da integridade que se reivindica quanto da coerência que se deseja imprimir a essa controversa biografia. Portanto, a dimensão subjetiva do sofrimento e sua legitimidade contemporânea são agenciadas nessas páginas de modo a desafiar e confrontar a linguagem dos direitos humanos. A memória mobilizada não diz respeito ao passado como se suspeitaria: trata-se de se viver sempre no tempo presente. A memória constrói um sujeito estático. $\mathrm{O}$ ressentimento veiculado e reivindicado - não é algo para ser superado - tem um lugar central, pois atualiza a missão divina de instituir um reino de deus na terra, com base no racismo militarizado, em um sexismo igualmente belicoso, na violência e na desigualdade. Os homens nesse cenário são literalmente à imagem e à semelhança de seu deus.

Recebido em 24/07/2015.

Aceito em 21/10/2015. 
Laura Moutinho é professora do Departamento de Antropologia e do Programa de Pós-Graduaçáo em Antropologia (PPGAS), ambos da Universidade de São Paulo (USP), doutora em antropologia cultural pela Universidade Federal do Rio de Janeiro (UFRJ), com pós-doutorado pela Universidade de Princeton, Estados Unidos (2013-2014). É bolsista de produtividade de nível 2 do Conselho Nacional de Desenvolvimento Científico e Tecnológico (CNPq). Compóe, como editora-chefe, o Comitê Editorial da Revista de Antropologia, da USP. Foi vicechefe do Departamento de Antropologia da USP e conselheira da Associação Brasileira de Antropologia (ABA). Foi pesquisadora visitante no African Gender Institut (AGI) da University of Cape Town (UCT), na África do Sul, e professora visitante do Public and International Affairs na Universidade de Princeton. Pesquisa e publica sobre antropologia e política, marcadores sociais da diferença, antropologia da África, direitos humanos, relaçôes raciais, gênero, sexualidade e identidade nacional na África do Sul e no Brasil. Publicou o livro Razão, cor $e$ desejo: uma análise dos relacionamentos afetivo-sexuais inter-raciais no Brasil e África do Sul (São Paulo: Editora Unesp, 2004), graças ao Prêmio Edusc/Anpocs de melhor tese de doutorado de 2003.Contato: 1moutinho@usp.br

\section{Notas}

* Este artigo é um dos frutos da pesquisa realizada para os projetos "On the other side? Das implicaçôes morais de certos horizontes imaginativos: raça/racismo, sexualidade, gênero e religião na África do Sul" (bolsa de produtividade em pesquisa de nível 2 do CNPq) e "Sob o comando de um deus racista: políticas sexuais na África do Sul", contemplado no edital MCTI/CNPQ/Universal 14/2014. Agradeço a Pedro Lopes pela leitura e discussão constantes. Agradeço a Wilson Trajano Filho a leitura cuidadosa, pelo apoio e pelas sugestóes.

1. Na ocasião, eu fazia trabalho de campo na Cidade do Cabo como parte do projeto "Entre a exclusão, o reconhecimento e a negociação: (homos)sexualidade e raça em uma perspectiva comparada internacional", que foi contemplado com bolsa de produtividade em pesquisa de nível 2 do CNPq, implementada em maio de 2009 (Edital MCT/CNPq/ SPM-PR/MDA no 57/2008, processo no 402916/2008-5). O objetivo mais amplo dessa pesquisa era buscar uma compreensão renovada acerca de convençóes, representaçôes e sociabilidades associadas a raça/etnia, sexualidade e gênero no Brasil e na África do Sul pós-regimes autoritários.

2. Neste artigo, optei por não traduzir as categorias raciais sul-africanas para o português. Com essa opção, gostaria de deixar clara para o leitor a importância de entender os termos de cor e raça nos seus contextos sociais e históricos. Meu objetivo, portanto, é evitar que haja um colamento de sentidos. Espero assim não transportar 
nem as classificaçóes raciais brasileiras, nem o sentido a elas atribuído e, menos ainda, o tipo de racismo vivido de um contexto para outro. O surgimento, a partir do período colonial inglês, da categoria étnica afrikaner (ou seja, sua etnicização e subsequente transformação em um nacionalismo) será parte da análise e, como não há paralelo em português, utilizarei a tradução. Na construção dessa autoidentificação étnica, são considerados afrikaners os descendentes white dos colonos holandeses, alemães e franceses (Ribeiro, 1995).

3. A Renamo (Resistência Nacional Moçambicana) lutou após a independência de Moçambique contra a Frelimo (Frente de Libertação Moçambicana), organização de esquerda que negociou com Portugal a independência. A Renamo recebeu apoio da África do Sul do apartheid, da minoria branca do atual Zimbábue e de outras forças tidas como conservadoras, que queriam desestabilizar o país e impedir o avanço do socialismo no continente africano. Essa disputa levou o país a uma guerra civil, que devastou Moçambique de 1976 a 1992. Ambas as organizaçóes são atualmente, no regime democrático presidencialista, partidos políticos. Para uma ideia matizada do conflito armado, ver as análises de José Luis Cabaço (2009) e Christian Geffray (1991).

4. Nelson Mandela foi o primeiro presidente eleito do pós-apartheid, em 1994. Com a força moral de um militante que lutou contra o regime e ficou 27 anos encarcerado, Mandela comandou o país até 1999, propondo-se a realizar a transição para a democracia e impedir uma temida guerra civil. Thabo Mbeki, sucessor de Mandela, governou até 2008, quando renunciou. Jacob Zuma foi eleito presidente da África do Sul em 2009.

5. O presidente Zuma é conhecido internacionalmente por ter respondido, ainda na condição de vice-presidente do país (meados da década de 2000), a processos de corrupção e estupro.

6. Ver também: Moutinho (2010); Moutinho \& Carrara (2010); Lopes \& Moutinho (2012).

7. A imagem é de uma "nação arco-íris", cujas cores permitem ênfase na diversidade — deslocando-se da noção antes reinante de raça ou mesmo de cultura e etnicidade.

8. Ubuntu é uma palavra bantu, de origem religiosa, que traz a ideia de humanidade compartilhada. Essa noção orientou a Comissão de Verdade e Reconciliação, que foi responsável pela investigação dos crimes do período do apartheid, pela reconciliação nacional e pelo reconhecimento das vítimas do regime (Moutinho, 2012, 2014; Ross, 2006; Tutu, 1999).

9. Ver Thompson (2001). A questão do poor white esteve na base dos argumentos que levaram à instalação do apartheid. Há, inclusive, quem nomeie o regime de segregação racial de "socialismo branco". Sobre a história dos africânderes, ver Giliomee (2003).

10. Como já argumentou Adhikari (2006), a história dos coloureds é complexa e muito pouco explorada na historiografia sul-africana. 
11. Terre'Blanche foi condenado a seis anos de prisão sob a acusação de tentativa de assassinato, após esmurrar um rapaz negro numa briga em um posto de gasolina. Ele foi solto em 2004.

12. Em realidade, seguindo a perspectiva de Juliana Braz Dias e And réa Lobo (2012), pode-se notar que a mobilidade e o deslocamento constantes pelo território sul-africano não apenas alteraram os limites morais, raciais e de gênero, trabalharam em favor de um tempo que se quer fixo.

\section{Referências bibliográficas}

ADHIKARI, Mohamed. 2006. "Hope, Fear, Shame, Frustration: Continuity and Change in the Expression of Coloured Identity in White Supremacist South Africa, 1910-1994". Journal of Southern African Studies, 32(3):467-487.

AGAMBEN, Giorgio. 2008. O que resta de Auschwitz: o arquivo e a testemunha (Homo Sacer III). São Paulo: Boitempo.

ALEXANDER, McGill. 2000. "The militarisation of South African white society, 1948-1990". Scientia Militaria, South African Journal of Military Studies, 30(2):267-289.

ARENDT, Hannah. 1989. Origens do totalitarismo. São Paulo: Companhia das Letras.

BRAZ DIAS, Juliana \& LOBO, Andréa de Souza (orgs.). 2012. África em movimento. Brasília: ABA.

CABAÇO, José Luís. 2009. Moçambique: identidade, colonialismo e libertação. São Paulo: Editora Unesp.

COCK, Jacklyn. 1993. "The place of gender in a demilitarisation agenda". Agenda: Empowering Women for Gender Equity, 9(16):49-55.

. 2004. "Rethinking militarism in post-apartheid South Africa". Crisis States

Programme. Development Research Center. Working Paper Series, 1:1-19.

CRAPANZANO, Vincent. 2000. Serving the word: literalism in America from the pulpit to the Bench. New York: The New Press.

DAS, Veena. 1999. "Fronteiras, violência e o trabalho do tempo: alguns temas wittgensteinianos". Revista Brasileira de Ciências Sociais, 14(40):31-42.

. 2007. Life and words: violence and the descent into the ordinary. Berkeley/Los

Angeles/London: University of California Press. 
DÖPCKE, Wolfgang. 1998. "Uma nova política exterior depois do apartheid? Reflexões sobre as relaçóes regionais da África do Sul, 1974-1998”. Revista Brasileira de Politica Internacional, 41(1):132-160.

DOUGLAS, Mary. 1966. Pureza e perigo. São Paulo: Perspectiva.

FOUCAULT, Michel. 1979. Microfísica do Poder. Org. Roberto Machado. Rio de Janeiro: Edições Graal.

GEFFRAY, Christian. 1991. A causa das armas em Moçambique: antropologia da guerra contemporânea. Porto: Afrontamento.

GILIOMEE, Hermann. 2003. The Afrikaneres: biography of a people. South Africa: Tafelberg.

HYSLOP, Jonathan. 1995. "White working-class women and the invention of Apartheid: 'purified' afrikaner nationalist agitation for legislation against 'mixed' marriages, 19341939". Journal of African History, 36:57-81.

LOPES, Pedro \& MOUTINHO, Laura. 2012. "Uma Nação de Onze Línguas? Diversidade social e linguística nas novas configuraçôes de poder na África do Sul”. Revista TOMO, 20:27-58.

McCLINTOCK, Anne. 2010. Couro imperial: raça, gênero e sexualidade no embate colonial. Campinas: Editora Unicamp.

MOUTINHO, Laura. 2004a. Razão, "cor" e desejo: uma análise comparativa sobre relacionamentos afetivo-sexuais "inter-raciais” no Brasil e na África do Sul. Sáo Paulo: Editora Unesp.

. 2004b. "Sexualidade, raça e direitos na África do Sul: primeiras reflexões". In: Adriana Piscitelli, Maria Filomena Gregori \& Sérgio Carrara (orgs.). Sexualidade e saberes: convençôes e fronteiras. Rio de Janeiro: Garamond. pp. 345-363

. (org.). 2010. Special Issue: Race and Sexuality in Different National Contexts - Brazil and South Africa. Sexuality Research and Social Policy, 7(4).

. 2012. "Sobre danos, dores e reparaçôes: The Moral Regeneration Movement - controvérsias morais e tensóes religiosas na ordem moral sul-africana”. In: Wilson Trajano Filho (org.). Travessias antropológicas: estudos em contextos africanos. Brasília: ABA. pp. 275-296.

. 2014. "Sob a ótica do feminino: raça e nação, ressentimentos e (re)negociaçóes na África do Sul pós-apartheid”. In: Alexandre Werneck \& Luís Roberto Cardoso de Oliveira (orgs.). Pensando bem: estudos de sociologia e antropologia da moral. Rio de Janeiro: Casa da Palavra. pp. 150-170. 
MOUTINHO, Laura \& CARRARA, Sérgio (orgs.). 2010. Dossiê Raça e Sexualidade em Diferentes Contextos. Cadernos Pagu, 35.

RIBEIRO, Luis Fernando Rosa. 1995. Apartheid e democracia racial: South Africa and Brazil in contrast. Tese de Doutorado, Universidade de Utrecht.

ROSS, Fiona. 2006. "La elaboración de uma Memoria Nacional: la Comisión de Verdad y Reconciliación de Sudáfrica”. Cuadernos de Antropología Social, 24 jul./dez.

THOMPSON, Leonard. 2001. A history of South Africa. London: Yale University Press. TRAJANO FILHO, Wilson. 2008. "O precário equilíbrio entre improvisação e regras: reflexôes sobre a cultura política da Guiné-Bissau”. Revista de Antropologia, 51:233-266. . 2011. "Goffman en Afrique: les cortèges des tabancas et les cadres de l'experience”. Cahiers d'Études Africaines, 201:193-236.

TUTU, Desmond. 1999. No future without forgiveness. New York: Doubleday.

WELSH, David. 1995. "Right-wing terrorism in South Africa". Terrorism and Political Violence, 7(1):239-264. 


\section{Resumo}

O objetivo deste artigo é explorar a linguagem que constrói a biografia de um conhecido líder nacionalista africânder que lutou contra o fim do apartheid, na África do Sul. Eugène Terre'Blanche - my side of the story pretende-se um testemunho e um retrato de e para um povo em sua luta para "manter a sua identidade e a sua liberdade". $\mathrm{Na}$ análise dessa narrativa, percorro os usos e os significados, tanto políticos quanto éticos, das ideias de tragédia e de sofrimento no sentido de dar inteligibilidade a um cenário que se coloca contra os direitos humanos, mas que retém um particular sentido de humano. As ideias-chave que delineiam as fronteiras dessa complexa cena são raça e religiáo, gênero e militarismo.

Palavras-chave: Eugène Terre'Blanche; militarização; raça; gênero; África do Sul.

\section{Abstract}

The main goal of this article is to explore the language used to compose the biography of a well-known Afrikaner nationalist leader who fought against the end of Apartheid in South Africa. Eugène Terre'Blanche - my side of the story is alleged to be a testimony and a portrait of and for a people in their struggle to "maintain their identity and their freedom". Analyzing this narrative, I examine the uses and meanings, both political and ethical, of ideas of tragedy and suffering in an effort to giving intelligibility to a scenario that is against human rights, but retains a particular sense of human. The key ideas that outline the boundaries of such complex scene are race and religion, gender and militarism.

Keywords: Eugène Terre'Blanche; militarization; race; gender; South Africa. 